through the usual stages of activity, decay, and re-utiliza-
tinin; while the silicious brain and the asbestos nerves quivtinin; while the silicious brain and the asbestos nerves quiv-
ercd with sensations of plcasure for ever denied to us com. ercd with sensations of plcasure for ever denied to us com
bustibles. Yet it is not too much to claim that no sufficient
reason can be given for confining the material out of which reason can be given for confining the material out of which
sentient beings can be constructed to the four type elements above referred to; nor is there any reason apparent
why a gradual change in the organs of assimilation as well should not accompany and compensate all gradual changes in the outside world, thus
rendering the thread of life continuous through beings more diverse than any that we yet know.-American Naturalist.

\section{ON THE SOFTENING OF MAGNESIA-HARD} By J. Grossmann, Ph.D.

I HA ve lately had an opportunity of making some experiments on the softening of so-called magnesia-hard water by
Clark's process. Although from a theoretical point of view there is no reason why such water should not be softened as ealily as ordinary (lime-)hard water, it was thought con-
venicnt to try the experiment on a somewhat large scale, especially as I have not been able to find that any experi-
ments on the softening of magnesia-hard water have been pullished before in detail.

lins Green, near St. Helens. The bottom of the well a!sout $961 / 2$ yards from the ground, and I give for com. a.
pleteness sake the different strata, as well as the quantity dissolved out of them, the samples being previously dried
at $240^{\circ} \mathrm{F}$.

$\left.\begin{array}{l}\text { Depth of alluvium and clay from } \\ \text { surface of ground to top of the } \\ \text { red sandstone.................... }\end{array}\right\}-$

Yellow sandstone

Compact red sandsto
New marl or metal..

$0 \cdot 16$
$0 \cdot 10$
$4 \cdot 72$

0.24
0.22
0.37
0.52
0.46
0.27

$\begin{array}{lll}\text { Coarse porous red sandstone........... } & 1.88 \\ \text { Coarse red sand................ } & 0.72\end{array}$

17

ours, taken from the time that the agitation was sus-
pended. From these experiments it follows that magnesia-hard Iinary (lime-)hard water.

I wish to point out here that in my opinion, with ou ward soap solution, the hardness test in cases of water of Wanklyn, in his book "On Water Analysis," says that maganklyn, in his book "On $\mathrm{Water}$ an $11 / 2$ equivalents of lime
would take up. If that were so the Collins Green water should have tested $35 \cdot 9^{\circ}$ total hardness, instead of $23 \cdot 3^{\circ}$, which it gave on the most careful testing. It will be noticed
that this is even less than the water would require if it con tained an equivalent of lime for the magnesia present; for me calculated hardness would then be $29 \cdot 4^{\circ}$. It appears to of the lime and magnesia is the only means of showing the quality of the water. On the other hand, I quite agrce
with Mr. Wanklyn in putting little reliance on the distinction between temporary and permanent hardness, unless the estimations have been performed very carefully; and there
are cases in which, even with the most careful working, figures for temporary and permanent hardnes
which are not trustworthy. - Chemical Neros.

THE INTRAVENOUS INJECTION OF AMMONIA. By Gaspar Griswold, M.D., House Physician to Bellevue

e physiological laboratory of Bellevue Medical College, I he action of intravenous injections of ammonia. For this per cent. of ammonia gas), diluting it with an equal bulk pungent and irritating, if dropped upon the tongue, is highly punsation caused by it passing away entirely in a few minsensation caused by it passing away entirely in a few min-
utes. I chose for experiment dogs in whom the viscera had
'been exposed for purposes of vivisection, and who had be. 2 come exlausted with loss of blood and the depression at

$\overrightarrow{961 / 2}$ tending the entrance of cold air into their thoracic and ab-

This water is organically very pure and contains only had almost ceased to beat, its rhythm being disturbed, and is almost entirely temporary, though in estimating the per-, pulsations. I then injected into a convenient vein half manent hardness it is sometimes difficult to remove the lime $i$ drachm of ammonia solution. After a period varyino with and magnesia by boiling. I may as well point out in this
plice a common fallacy, which is that hard water by being
boiled before being used for domestic purposes becomes soft. As it is generally only heatted to boiling just before being used for washing or cooking it makes not much difference
in the hardness of the water. The following is taken from the sixth report of the Commissioners appointed in 1868 to
inquire into the best means of preventing the pollution of rivers. Thirteen samples of water drawn on thirteen differ
ent days from the kitchen boiler of a dwelling house, and ent days from the kitchen boiler of a dwelling house, an
from that of the Athenæum Club, were found to be usually nearly as hard as the coler from the follow sults :

\begin{tabular}{cc|cc}
$\begin{array}{c}\text { Hardness of } \\
\text { cold water. }\end{array}$ & $\begin{array}{c}\text { Hardness of } \\
\text { hot water. } \\
14 \cdot 6\end{array}$ & $\begin{array}{c}\text { Hardness of } \\
\text { cold water. } \\
15 \cdot 4\end{array}$ & $\begin{array}{c}\text { Hardness of } \\
\text { hot water. } \\
14 \cdot 3\end{array}$ \\
$14 \cdot 4$ & $13 \cdot 9$ & $15 \cdot 9$ & $11 \cdot 9$ \\
$14 \cdot 4$ & $13 \cdot 4$ & $16 \cdot 1$ & 11.9 \\
$14 \cdot 6$ & $11 \cdot 6$ & 18.7 & $18 \cdot 4$ \\
$14 \cdot 6$ & $7 \cdot 6$ & $18 \cdot 7$ & $18 \cdot 6$ \\
$14 \cdot 4$ & 11.7 & $18 \cdot 7$ & $18 \cdot 4$ \\
$14 \cdot 4$ & $12 \cdot 1$ & - & -
\end{tabular}

I boiled Collins Green water that tested $27.8^{\circ}$ total hardness in an ordinary tea-kettle for five minutes, and even that total hardness. The experiments for softening this water by Clark's process were made in two series; in the first milk
of lime was used, and in the second lime water. The milk of lime was prepared by mixing $5 \mathrm{lb}$. of slaked lime of 70 of cent. CaO with 6 gallons of Collins Green water. In
performing the softening of the water the milk of lime was gradually added to the water during the operation, the
mixture being well agitated during the whole experiment. mixture being well agitated during the whole experiment.
In three experiments the hardness was reduced from $23 \cdot 3^{\circ}$, In three experiments the hardness was reduced from $23^{\circ} 3^{\circ}$
which the water tested originally, to $5 \cdot 0^{\circ}, 5 \cdot 5^{\circ}$, and $5 \cdot 7^{\circ}$ The total solids were reduced respectively from 33.9 to $13 \cdot 0$, $33 \cdot 6$ to $12 \cdot 2$, and $33 \cdot 6$ to $13 \cdot 6$ grs. per gallon. The softened
water, after it had been standing in stoppered bottles for a
few days, formed a little deposit, and its hardness was then few days, formed a little deposit, and its hardness was then
$35^{\circ}$ in all cases. The analysis showed that then the lime had been reduced from $9 \cdot 13$ to $1 \cdot 62$; the magnesia from $5 \cdot 23$ (1) 23 gr. per gallon. There were used on an average 1,465 gallons of water to $3.5 \mathrm{lb}$. of $\mathrm{CaO}$, corresponding to $2.67 \mathrm{lb}$. of lime of 90 per cent. per 1,000 gallons. Theoretically to precipitate the
lime and magnesia as far as I have done in my experiment would require $2 \cdot 31 \mathrm{lb}$. of $\mathrm{CaO}$ per 1,000 gallons. The experiments for softening with lime water were car-
ried out in a similar way. A measured quantity of the lime
water was put into the mixing tank, and the Collins Green water was put into the mixing tank, and the Collins Green
water run into it until nearly all the lime of the former was taken up, which in these experiments as well as in those test. The mixture was well agitated during the whole experiment. A great advantage in working with lime water Ine. which the water tested originally, to $3 \cdot 5^{\circ}, 33^{\circ}, 3 \cdot 5^{\circ}$, and $3 \cdot 5^{\circ}$. The total solids were reduced respectively from $34 \cdot 3$ to $12 \cdot 0$, $34 \cdot 4$ to $11 \cdot 2,34 \cdot 6$ to $12 \cdot 0$, and $34 \cdot 7$ to $11 \cdot 2$. The lime had
been reduced from $9 \cdot 07$ to $1 \cdot 67$, and the magnesia from $5 \cdot 24$ to $0 \cdot 18$ grs. per gallon.

There were used on an average 1,670 gallons of water on
530 gallons of lime water, which latter having been exposed to the air for some time before being used tested only 6) grs. $\mathrm{CaO}$ per gallon. This corresponds to one volume of lime first in next case deserves more careful attention, being th water of 60 grs. $\mathrm{CaO}$ per gallon to $3 \cdot 15$ volumes of Collins enough to sittisfy myself that no bad effects follow the inGreen water, or corrected to 90 grs. of $\mathrm{CaO}$ per gallon,
which strong lime water should contain, the proportion of ammonia directly into the circulation.
lime water to Collins Green water would be 1 to 4.72 . This result is not quite correct, as the lime water had undergone ascites, which had commenced a month before, and was proa further susceptible decomposition while lying in the mix- bally due to cirrhosis of the liver Right pleural cavity
in $\sigma$ tank; so that at the time of its action on the Collins pcarly full of fluid, heart displaced to the left. No evidence Green water it contained less than $60 \mathrm{grs}$. $\mathrm{CaO}$ per gallon. of curdiac or renal disease. Patient very weak, and com-
$\mathrm{B}^{\prime}$ th in working with milk of softened water settled perfectly clear after three to five men tapped, seven quarts and eight ounces of clear serum immediately re-established, and the animal, if anæsthesia immediately re-established, and the animal, if anæsthesia
the course of fifteen or twoved and showed signs of life. In obtain the result above described.

In my wards in Bellevue Hospital, I have several times
injected one drachm of ammonia solution into the veins of patients apparently moribund, and have al ways succeeded by other methods. The prompt and marked effect in some see hypodermic injections of whisky and ether, inhala-
and Oircumstances. On one occasion a man came in a great hurry, having been
Oified that his brother was dying of phthisis in one of my ards. Notwithstanding his haste, the sick man was al
eady moribund and unconscious when he arrived. Pitying injected a drachm of ammonia solution into my patient's
cephalic vein. In five minutes the man who bad appeared cephalic vein. In five minutes the man who lad appeared
almost dead was sufficiently restored to speak, and haif an hour elapsed before he again became unconscious. The ef-
fect of the stimulant was so marked that I had some diffculty at first in convincing the astonished visitor that his
brother had not "taken a turn and was getting well Case.-Man forty-five years of age, with cirrhosis of liver and ascites. Has been tapped three times, fluid reaccumuscarcely perceptible; surface cold and moist. 2d. Six half drachm doses of ether administered hypo-
ermically. No effect

3d. Inhalation of ammonia. No effect.
4th. Inhalation of nitrite of amyl. Slight increase in
orce and rapidity of pulse No sign of returning con5th. One drachm of ammonia solution injected into a ction of heart. Pulse good at wrist. In three minutes
ction atient answered incoherently something about being un-
mfortable, and tried to turn on his side. Could be roused nd his attention attracted, for about fifteen minutes; the became unconscious again. Died half an hour later.
Case.-Moribund from phthisis. Unconscinus; heart Cting very feebly. Intravenous injection of ammonia
caused the heart to act vigorously, and partially restored Three cases, like the last, presenting no feature worthy of Three cases, like the last, presenting no feature worthy of

withdrawn. Patient much relieved. Stimulants and nuMay 1st.-Patient very weak. Does not seem to suffer much from dyspnœa, though the right side is nearly full May 3d.-Patient still very weak. Dyspnœa not May 4th.-Called by nurse to see patient. Found her reathing very little; weakness seeming to obscure the ex made to notice anything, or swallow what is put to her lips. Fluids poured into her mouth run out again. Eyes vacant Thoracentesis performed with the assistance of three mem-
The dilated; ja w fallen; tongue dry and brown. rs of the house staff. Ninety ounces of clear serum During the cperation, which lasted about twenty minDuring the cperation, which lasted about twenty min-
utes, fifteen or twenty half drachm doses of whisky were dministered hypodermically. In spite of these efforts at
timulation, the pulse, which had before been weak, disap. peared entirely at the wrist. The impulse of the heart could
the eared entirely at the wrist. The impulse of the heart could
carcely be felt over the præcordia, and the respirations inflation of the lung just relieved from the pressure of my colleagues of the house staff, who had been assisting me were of opinion that she was dving, and that further treatment was uscless, and even alsurd. Fxpressing themselves
to this effect, they left me, giving up the case in their own minds, and taking no further interest in the matter. While by ordinary standards, and beyond the reach of crdinary stimulants, I could not help feeling that heroic measures
were specially indicated. The source of trouble-fluid com pressing a lung and displacing the heart-had been removed; f the patient could be stimulated to breathe decply, and
profit by its disappearance, there seemed to be good reason Selecting a prominent superficial vein in the radial reion, I exposedit by an incision through the skin. I then njected slowly into it a drachm of ammonia solution, tak-
ing care that the point of the hypodermic needle was free n the lumen of the vessel. This done, I placed my hand
orer the patient's beart and waited. In fifteen seconds I felt marked increase in the force of pulsation. In about two
minutes there was a strong pulse of a hundred, which was plainly perceptible at the wrist. A minute later the patient plainly perceptible at the wrist. A minute later the patien
sigled deeply; the color came back to her lips; her eyes moved and began to show signs of returning intelligence.
On being urged, she swallowed without difficulty two On being urged, she swallowed without difficulty two
ounces of strong egg-nog. After a few deep inspirations, she breathed more regularly and easily; her pulse was strong
and tense, ranging between 100 and 110 . Half an hour afterward she was perfectly conscious, and reported herself comfortable, though weak. Pulse 90, regular and strong.
Respirations 26, easy and natural. Swallowed easily and Respirations 26, easy and natural. Swallcwed easily and
willingly small quantities of egg-nog. During the after-
non and evening patient continued to improve. Pulse $80-$ noon and evening patient continued to improve. Pulse 80-
00, and strong. Respiration 2C-30, and easy. Patient passed a gond night, sleeping most of the time. Was bright and refreshed in the morning.
May Tth. $^{\text {th }}$-Steady improvement since last note. Sat up or two hours to day and ate a lamb chop with relish.
May 17th.-Patient sits up nearly all day and is gaining N. B.-Improvement bas heen uninterrupted since the in jection of ammonia. No depression has been observed folcurred an unpleasant symptom which could be attributed The cases described seem to satisfactorily establish: 1. That the intravenous injection of ammonia is a prompt
and powerful means of stimulation, acting efficiently in 2 . That no bad effects follow its employment
W

While the importance of the above deductions is obviou have a special significance in connection with those operations whose object is the removal of mechanical obstructions to respirations-I mean thoracentesis, and more partiperbaps, very often an emergency; but laryngotomy and
and tracheotomy, done in cases of croup, œdema glottidis, etc.,
generally fail to save life, because performed too late- the patient being too much exhausted to breathe in the air for hypodermics of whisky and ether, cold affusions, etc., are cannot be set in motion again, and the cases die for want of efficient stimulation. Now, would not the intravenous injection of ammonia, in connection with artificial respiration,
save many of these patients? It being proved that the treatment is without danger and followed by no In conclusion, I would call attention to the fact that it is not easy to perform intravenous injection through the skin.
The vein collapses under the necessary pressure, and the The veln collapses under the necessary pressure, and the all, or to transfix it and direct the injection into the cellular
issue beyond. The only safe method to pursue is to dis. issue beyond. The only safe method to pursue is to dis-
sect down upon the vein and expose it; the needle may then be carefully introduced until the point is felt free in the in-
erior of the vessel.-Medical Record.

REMARKABLE FIRE CAUSED BY LIGHTNING.

Is the storm of June 11th, at 10.30 A.M, lightning struck river, at the petroleum refinetry of the Atlantic Refinery and of Market street, Philadelphia. This company has the perhaps the largest in the world. Some accounts state that
the electricity first struck the can store-house on the wharf. Others, with more prohably correct statement, declare it
struck first an immense pile of about 30,000 tin cans contruck first an immense pile of about 30,000 tin cans con-
taining refined petroleum, exposed uncovered on the wharf, Each wooden case contained two five
allon cans. The American Exchange nnd Revievo says: The pile of cans was more probably the point of origin of the fire, because tract electricity, while all the buildings and tanks wer well protected by lightning rods.
[There was, of course the

The usual percentagre of leakage from the cans, and we think it probable that the light vapor
from the petroleum, which rises to a great height, formed the conductor which directed the lightning to the cans.] 